\title{
An Analysis of the Factors Affecting Public Participation in Environmental Impact Assessment: Case Study of Selected Projects in Nairobi City County, Kenya
}

\author{
Onyango Leah Atieno, \\ Student, Faculty of Arts and Social Sciences \\ Department of Development Studies, The Catholic \\ University of Eastern Africa, Kenya \\ Dr. Frida Nyiva Mutui, \\ Mr. Evans Wabwire, \\ Lecturers, Department of Geography and Environmental Studies, \\ The Catholic University of Eastern Africa, Kenya
}

Doi: 10.19044/esj.2019.v15n9p284 URL:http://dx.doi.org/10.19044/esj.2019.v15n9p284

\begin{abstract}
Public Participation (PP) is an integral part in the EIA process and it is enshrined in the Constitution of Kenya. The overall objective of the study is to evaluate the factors that affect public participation in EIA process among selected projects in Nairobi City County. The specific objectives of the study were to evaluate how socio- economic, behavioral and political factors affect $\mathrm{PP}$ in EIA process. Two theories that were used in this study included OECD active participation framework and CLEAR participation model. The study adopted descriptive research design. The researcher targeted five projects from 53 on- going projects in Nairobi County. The population of the study included 105 respondents (100 participants and 5 project proponents). That is 20 respondents from each project. The researcher used questionnaires (participants) and interviews guides (project proponents) to collect data. Data collected was both quantitative and qualitative. The findings revealed that the level of education affects public participation in projects. Language used during meetings could either encourage/ discourage effective communication hence have an effect on participation. Employment status tend to affect how public participate in EIA process. The level of trust between the government and public tends to affect how the public will come out to participate in government projects when called upon. Politicians had an influence on public participation in government projects. The study recommends regularly awareness by National Environment Management Authority about EIA
\end{abstract}


process and the public should change their attitude towards participation in government projects.

Keywords: Public Participation, Environmental Impact Assessment

\section{Introduction}

Public participation is an integral part in the Environmental Impact Assessment (EIA) process. It involves the public being provided with relevant information about the proposed project/plan, giving their views about the proposed plan and right to go to court especially if there are any deficiencies occurring during / after the EIA process. The purposes of public participation are to promote transparency, encourage openness in the process and build ownership of development decisions as well as programs and projects. It encourages citizens to be more engaged in the decision-making processes that have an impact on their local community. It also serves to advance citizens' understanding of how governmental decision-making processes. Public participation provides the public with the opportunity to influence and participate in development programs and projects (United NationsHABITAT, 2001).

Over the last decade, international agreements on the environment were held and public participation in environmental decision-making has been on the spotlight. Under Principle 10 of the Rio Declaration held in 1992, it emphasizes the importance of public access to information, participation in decision-making processes and access to judicial procedures and remedies. In Agenda 21, the plan of action that accompanied the Rio Declaration, governments pledged themselves to the pursuit of broader public participation in decision-making processes and policy formulation for sustainable development (Webler \& Krueger, 2001). Aarhus Convention held in 1998 focused on three pillars that is; Access to information, Public participation in decision- making and Access to justice in matters to do with the environment. The three pillars evolved from the Rio Declaration (United Nations Economic Commission for Europe, 2006). Based on the second pillar, the public ought to be informed about the relevant projects for them to be given a chance to participate during the decision-making and legislative process. Decision makers can take advantage from people's knowledge and expertise and this contributes to improved quality of the environmental decisions, outcomes and guarantees procedural legitimacy (Rodenhoff, 2003).

Few African countries like Nigeria, South Africa, Tunisia, Malawi, Zimbabwe and Uganda have frameworks that guide public participation in EIA while in other countries has no frameworks. With the enactment of the EIA legislation in different countries, this is seen as a huge milestone in achieving effective PP in EIA process. In Malawi for instance, the adoption of 
Environment Management Act of 1996 has made EIA to be carried out in major development projects. However, the level of public participation on EIA issues in such development projects in Malawi is far from clear. This is due to lack of public information on the development projects (Kosamu et. al, 2013).

Although most countries around the world have enacted legislation that provide mechanisms for engaging and involving the public throughout the EIA process, there are challenges in implementing effective public participation. Illiteracy, negative attitude, language barriers, cultural barriers, lack of adequate information are some of the barriers that hinder the public from participating in the EIA process. The major factors influencing EIA practice appear to be poor engagement with stakeholders in Uganda include; the negative perception of EIA held by developers, lack of capacity to conduct environmental audits and enforcement, weak institutional linkages and political interference (Kahangirwe,2011). The constraints towards public participation in EIA practice Tanzania include; insufficient time, sociocultural factors (Tanzanians consider themselves a non-participatory society), misconceptions about EIA by the public and mistrust (Pallangyo, 2005).

According to National Environment Management Authority (NEMA), public participation within EIA in Kenya is well known as consultation and public participation. Four documents that guide PP in EIA process in Kenya include; Constitution of Kenya (CoK), Environmental Management Coordination Act (EMCA), Environmental Impact Assessment Guideline \& Administrative Procedures(EIAGAP) and Environmental Impact Assessment \& Audit Regulations (EIAAR). CoK has no specific provisions regarding the environment. It however, stresses on the right to life. Right to life would be interpreted as a right to a clean and healthy environment. EMCA, EIAGAP \& EIAAR provide an appropriate legal and institutional framework for the management of the environment. EMCA clearly states in the second schedule the projects in which an EIA has to be conducted. EIAGAP \& EIAAR ensures that the affected persons are involved throughout project cycle (NEMA, 2014).

Practical effectiveness of public participation has not been achieved in Kenya. This is because superficial PP has been conducted in major projects leading to Non- Governmental Organizations (NGOs) coming on board since they have a greater influence in bringing environmental issues relating to projects to the attention of the local press. The Nairobi Southern By-Pass project met fierce opposition by a lobby group who viewed that construction of the road through national park who eat some part of the park. This lead to the project being stopped temporarily until the issue was resolved (Ngonge, 2015). 


\subsection{Statement of the problem}

Majority of projects initiated by the government are supposed to be subjected to an EIA study do not go through this process. If they go through the process, the aspect of public participation is left out. NEMA has issued EIA licenses for the commencement of these projects which are not environmentally sustainable. These projects end up causing more harm than good in the ecosystem. These projects are the main cause of pollution of land, air and water bodies. Human, plants and animal are at risk once these projects are completed. The public have lost their land especially in projects involving road and railway construction. The trees have been cut to pave way for large infrastructural projects. There has been pollution of air especially in completed projects that involved manufacture of heavy chemicals. Members of the public at the start of these projects raise issues about these projects. This has led to temporary stoppage of these projects due to court injunctions issued to project proponent. Later on the public experience delay of delivery of social services because a lot of time and money is wasted in court cases pertaining to these projects. The construction of Standard Gauge Railway phase two is just a recent example. One may wonder if effective PP took place in the EIA Study for these project then issues to do with protest and court cases would not arise. Hence in this research, the researcher attempts to evaluate the factors that affect public participation in EIA process by focusing on selected projects in Nairobi City County.

The study was guided by the following objectives;

1. To determine whether socio- economic factors affect PP in the EIA process in selected projects in Nairobi City County.

2. To examine whether behavioral factors affect PP in the EIA process in selected projects in Nairobi City County.

3. To determine whether political factors affect PP in the EIA process in selected projects in Nairobi City County. 


\subsection{Conceptual Framework}

Independent Variables

\section{Socio- Economic Factors \\ - Education \\ - Language \\ - Income Level \\ Behavioral Factors \\ - Trust \\ - Attitude \\ Political Factors \\ - Political Interference}

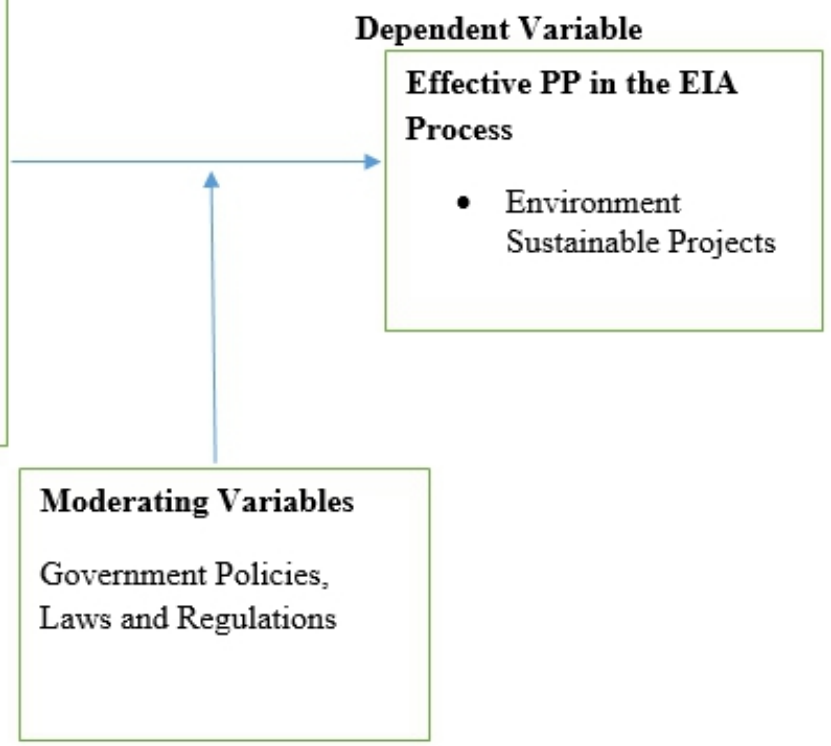

Figure 1: Conceptual Framework showing independent and dependent variables Author, 2018

The conceptual framework presented in Figure 1 above, aimed at addressing the research questions. It illustrates the variables involved in the study. They include; dependent, independent and moderating variables. The independent variables include the socio- economic factors, behavioral and political factors. The socio- economic factors comprise of education, language and literacy levels. The behavioral factors comprise of trust and attitude. The political factors comprise of political influence. The dependent variable include effective public participation in EIA process. The intervening variable include government policies, laws and regulations.

\section{Literature Review}

\subsection{Critical Review of Relevant Theories}

OECD- Active Participation Framework- It was developed by Organization for Economic Co-operation and Development (OECD) in 2001 as a means of strengthening the relationship between the government and citizens in policy making issues. This is done through information sharing, consultation and active participation. According to the model, information 
sharing is one-way relationship in which the government produces and delivers information to its citizens. Consultation is a two- way relationship in which the citizens provide feedback to the government. Active participation is a relationship that is based on partnership with the government, in which citizens actively engage in defining the process and content of policymaking.

It acknowledges equal standing for citizens in setting the agenda, proposing policy options and shaping the policy dialogue- although the responsibility for the final decision or policy formulation rests with the government. The framework is applicable to this study because it brings on board both the government and the citizens and their contribution they have to make in order for successful participation to be achieved with regards to the issue at hand. It shows us how effective public participation ought to be conducted.

The strength of this model is that it encourages openness and transparency between the government and its citizens and this is noted through the strengthening of the relationship between both parties. Secondly, it gives all interested parties a chance to contribute in decision - making issues and hence the government is able to increase its chances in voluntary compliance.

The weaknesses of this model is that; there's delay in decision making because the government tends to involve all interested parties in making contribution in decision - making issues. For effective PP to be achieved, it is important to take the views of all interested parties. However, this leads to delays in arriving at a final decision on the proposed project. Secondly, though the citizens are given a chance to make their own contribution, they do not get feedback once the final decision is made. The interested parties of the proposed project do not get a chance to have a closing meeting to know what issues were considered. Thirdly, this model tends to assume that all citizens are literate. There is no training for the citizens before they make their own contributions.

The CLEAR Participation Model- The model was developed by Lowndes and Pratchett in 2006. Through the model, government organizations or civil society organizations are able to better understand social participation in their communities or among their stakeholders. It argues that participation is most successful if these five factors are in place; Can do, Like to, Enable to, Asked to and Responded to. Under Can do, ensures that citizens have the resources and knowledge to participate. Like to, ensure that citizens have a sense of attachment that reinforces participation. Enabled to, ensure that citizens are provided with an opportunity to participate. Asked to, it is all about mobilizing people into participation by asking for their input. Responded to, finally means that people will want to see evidence that their views have been considered. This model is suitable in this study because it brings on board five 
factors that will enhance successful participation in EIA process. The model put so much emphasis on placing the public as the focus of attention.

The strength of this model is that it takes a holistic view that is; the model is interested in engaging and developing the whole person. If the public lack the necessary skills, they are trained. For effective PP to be achieved, the interested public ought to have necessary skills to be able to participate. The model is against ignoring those who lack necessary skills because it emphasizes on training of those who will make their contribution pertaining to the project. Secondly, the model also recognizes the importance of public participation by placing the public as the main center of attention. The public are provided with relevant information about the proposed project, the public are offered training, the public are offered with proper communication channels and they are also called upon to participate in meetings.

The weaknesses of this model; it is too abstract hence it is difficult to apply it in an ideal situation. Even though this model is a gateway to achieving effective PP, it is difficult to achieve all these. Secondly, incase all ideas about this model are put into practice; the public participation would be a costly affair.

\subsection{Socioeconomic Factors affecting PP in EIA Process}

Education and literacy go hand in hand although literacy is generally associated with the ability to read and write. Education on the other hand requires application of skills in a real world setting. Our education levels tend to shape our way of thinking, how we are able to express our ideas and how we discuss issues during meetings. There is a direct correlation between public participation and educational background of the public. People with a higher level of education can to a large extent possess good literacy and communication skills and therefore tend to participate more readily and actively in the EIA process since they can provide useful suggestions and opinions (Zhao, 2010).

Low education levels attained as noted by projects committee members is the main reason to poor sustainability of projects in Kiambu County, Kenya (Wathome, 2013). The study further noted delayed provision of training programs to the committee members in equipping them with necessary skills on project management. In some cases, trainings to the members of the committee failed to take place. However, where the trainings were organized, some stages in the project cycle failed to take place.

Language differences hinder effective communication. Public participation is an open, ongoing and a two- way communication between government and its citizens. Interactive communication enables both parties to learn about and better understand the views and positions of the other. In a study conducted in the USA about a project in Minneapolis, language barrier 
in Minneapolis area did not arise. The Metropolitan Council employing students at the University of Minnesota who were fluent in the region's widely spoken foreign languages (primarily Spanish and Somali) to canvas neighborhoods and go to door-to- door to discuss and provide information about the project in resident's native languages (U.S. Department Of Transportation, 2010). Similarly, language barrier is a factor that hinders many of the participants when citizens attend these forums. They are required to express themselves in Lugha ya Taifa (Kiswahili) which they are not confident in expressing themselves in. Most of the documents are wrote in English language and thus those who cannot read and comprehend end up not to attend the public participation meetings (Kalekye, 2016).

There is a general assumption that higher the income level, higher the participation. As a result, it can be said that lower income level affects participation. Higher income earners tend to dominate discussions in public meetings because of their economic status and their influence in the society unlike the low-income earners. However, in some cases, the unemployed category tends to have more time at their disposal and they will be seen in meetings when called upon to participate. Generally, there is an unequal representation due to biased approach. This is because representation is based on what you possess and not your ideas. Income is closely associated with participation even when taking account of gender, type of family, employment status, ethnic group, educational levels, and region of residence (Ferragina et. al, 2013).

\subsection{Behavioral Factors affecting PP in EIA Process}

Attitude determines how the members of the public will come out to participate upon invitation. Negative attitude probably stems out from experiences, which lead to feelings of frustrations and disappointments by the public. If these experiences were not dealt with, they tend to shape future experiences. With the negative attitude in the minds of the public, it is unlikely that the proposed project will get support from the members of public. Failure of the project proponent to deal with unresolved past conflicts creates hostility and animosity to new projects implemented by the same proponent. Studies by the World Bank in Bosnia and Herzegovina established that even though a large number of citizens were not satisfied with their representation in municipal or local authorities' activities, a small minority were willing to participate in such activities. Their participation in local government was limited largely because citizens did not believe they could influence local decision-making. As a result, public participation was more reactive than proactive (World Bank, 2009).

With a positive mindset, success of the project is likely to be achieved due to the support of the public. South Africa is the most successful country 
in Africa with regard to effectiveness of public participation in EIA. This is because both the public and private sector in South Africa are knowledgeable on the importance of public participation. Private- Public partnerships have helped develop the knowledge (Aregbeshola, 2009). According to a study conducted in Garissa County about community participation in the implementation of development projects, the findings revealed that the community around were not involved in the management of Sewerage development projects. People from other areas managed the project while the local people did not appreciate community development and their attitudes towards participating in community development projects were not favorable (Ali, 2018).

Trust primarily makes people to have confidence about people or organizations. Positive expectations towards people or organizations make people to be more trustworthy. People tend to build trust on consistent delivery on promises along with other factors. Public trust is influenced by behaviors that display integrity, openness, loyalty, competency and consistency. Trust formation in the public sector is influenced by behavioral factors of two main behavioral characteristics of public administrators. First, participation influences trust when participation produces quality services that the public desire, and second, enhanced ethical behavior on the part of public administration is another key reason that participation leads to trust (Wang, 2007).

Public participation builds trust and support. There is little chance of a plan that has no "ownership" by the citizenry of being effective and successful. To care is to build trust. People care less about what you know professionally until they know how much you care about their welfare. Building trust between the public and other stakeholder helps to develop a sense of ownership and responsibility towards the project (Abiodun, 2016).

\subsection{Political Factors affecting PP in EIA Process}

Politics tend to take center stage during participation especially if the government initiates the project and the politicians have an upper hand in the government. In a study conducted in Zambia, what came out clearly is that the government has been slow to decentralize its structures to encourage local participation since independence in 1964 and the population has been accustomed to a top down approach in participating in public matters. The past one party - state -governance culture is also an obstacle in the sense that it brings back memories of fear and victimization in the minds of the population. This reality instils a sense of caution towards public participation and is a feature that continues to manifest itself in the current governance milieu of the country. To participate in various public spaces, a person has to be on the correct political side. However, with an evolving political culture and a 
younger generation taking over leadership, it is more likely that this culture will slowly die away (Munyinda and Habasonda, 2013).

According to a study conducted in Uasin Gishu County, there was a clear indication that public participation in the County was very low and that it involved residents giving their opinions, which the government did not consider properly when initiating development projects. The residents felt that the development projects undertaken by their county government were not reflective of their needs given that majority of them had not participated in any public forum (Gitegi, 2016).

\section{Research Design and Methodology}

The study used descriptive design. Data was obtained from both primary and secondary sources. The primary data comprised of information collected from the participants of the selected projects. Structured questionnaire was used to collect primary data. Secondary data was obtained from the EIA Study report of the 5 selected projects that is; Nairobi River Sewerage Improvement project, Nairobi Outering Road Improvement project, Ngong Road Dualling Phase II, Construction of Waiyaki Redhill Link Road and Ngong Road - Langata Link and Enhancing the capacity of Likoni RoadLunga Lunga Road Upgrade.

Among the 53 projects that were initiated by the Government and only 5 large infrastructural projects were selected as case study. The sample of 5 was selected using convenient sampling because data from these five projects was readily available. From the 5 projects, the researcher had 100 participants as sample size. Since this is a descriptive study, according to Mugenda \& Mugenda (2003), 10\% - 30\% is considered adequate for descriptive studies. In this study, the researcher targeted participants in the 53 ongoing projects in Nairobi County in which the EIA study has been conducted and NEMA license was issued to them. 20 is the number of participants who were consulted during the EIA process according to the EIA reports from NEMA. The study used questionnaires as the main tool for data collection. The use of questionnaires enabled the researcher to reach the 100 respondents and it gave the respondents freedom to express their views. The questionnaire had both open- ended and close- ended questions. Interview guide was also used in the study as means of collecting data from the project proponents in order to get better understanding of the factors that affect the effectiveness of public participation in the EIA process. 


\section{Data Presentation and Interpretation of Findings}

\subsection{Socio- economic factors affecting PP in EIA process}

\subsubsection{Extent to which education level affects participation}

From the NaRSIP, $70 \%$ of the respondents agreed that education level affect participation to high extent while $30 \%$ agreed to a low extent. From the NaORIP, $65 \%$ agreed that education level affect participation to high extent while 35\% agreed to a low extent. From the NgRDP, $78 \%$ agreed that education level affect participation to high extent while $22 \%$ agreed to a low extent. From the WR, 75\% agreed that education level affect participation to high extent while 25\% agreed to a low extent. Finally, from the LL project, $79 \%$ agreed that education level affect participation to high extent while $21 \%$ agreed to a low extent. Results of respondents' are shown below in Figure 2.

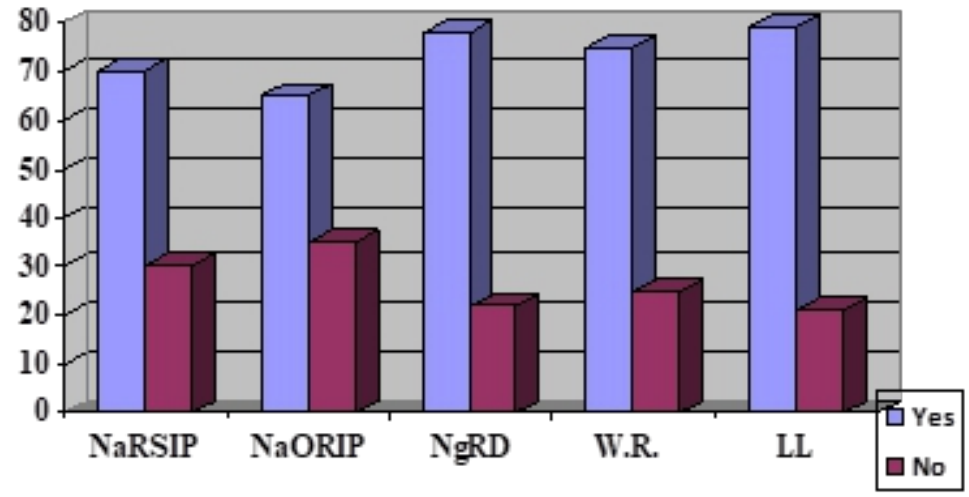

Figure 1: Extent to which education level affects participation

Source: Author's (2018)

Key: NaRSIP- Nairobi River Sewerage Improvement

NaORIP- Nairobi Outering Road Improvement

NgRD- Ngong Road Dualling Phase II

W.R. - Waiyaki Redhill Link Road \& Ngong Road - Langata Link

L.L. - Likoni Road- Lunga Lunga Road Upgrade

\subsubsection{Convenient mode of communication about information relating to the project}

From the NaRSIP, $66.7 \%$ of the respondents agreed that radio is the convenient mode, $26.6 \%$ agreed that social gatherings is the convenient mode and $6.7 \%$ agreed that posters is the convenient mode. From the NaORIP, $66.7 \%$ of the respondents agreed that radio is the convenient mode, $33.3 \%$ agreed that social gatherings is the convenient mode.

From the $\mathrm{NgRDP}, 75 \%$ of the respondents agreed that social gatherings radio is the convenient mode and $25 \%$ agreed that radio is the convenient mode. From the W.R., 70\% agreed that radio is the convenient mode and 30\% agreed that social gatherings is the convenient mode. Finally, from the JKIA project, $57.1 \%$ of the respondents agreed that social gatherings 
is the convenient mode, $28.6 \%$ agreed that radio is the convenient mode and $14.3 \%$ agreed that posters is the convenient mode.

Most of the respondents in the NaRSIP, NaORIP and W.R.projects indicated that radio as the most convenient mode of communication that information relating to the project would be conveyed. Most argued that radio tends to reach a large population. There vernacular stations for people who are illiterate since it involves listening. The respondents from NgRDP and L.L.project preferred social gatherings. They pointed out that it is cheap and people tend to pay more attention to one on one kind of communication than these other modes. Few respondents who suggested posters as convenient mode argued that they are cheap and can reach a large mass of people. Results of respondents' are shown below in Table 1.

Table 1: Convenient mode of communication about information relating to the project

\begin{tabular}{lccccc}
\hline Mode & NaRSIP & NaORIP & NgRD & W.R & L.L \\
\hline Poster & $6.7 \%$ & $9.9 \%$ & $25.4 \%$ & - & $14.3 \%$ \\
Newspapers & - & $5.5 \%$ & $7.7 \%$ & - & - \\
Radio & $66.7 \%$ & $66.7 \%$ & $25 \%$ & 70 & $28.6 \%$ \\
Television & - & - & - & - & - \\
Internet & - & - & - & - & - \\
Social gatherings & $26.7 \%$ & $33.3 \%$ & $75 \%$ & $30 \%$ & $57.1 \%$ \\
Total & $\mathbf{1 0 0 \%}$ & $\mathbf{1 0 0 \%}$ & $\mathbf{1 0 0 \%}$ & $\mathbf{1 0 0 \%}$ & $\mathbf{1 0 0 \%}$ \\
\hline
\end{tabular}

Source: Author's (2018)

\subsubsection{Employment Status}

From the NaRSIP, $66.7 \%$ of the respondents agreed that unemployed are likely to participate, $26.6 \%$ agreed that the employed are likely to participate and $6.7 \%$ agreed that the self-employed are likely to participate. From the NaORIP 53.3\% of the respondents agreed that unemployed are likely to participate, $33.3 \%$ agreed that the employed are likely to participate and $13.3 \%$ agreed that the self-employed are likely to participate.

From the $\mathrm{NgRDP}, 50 \%$ of the respondents agreed that unemployed are likely to participate, $33.3 \%$ agreed that the self -employed are likely to participate and $16.7 \%$ agreed that the employed are likely to participate. From the W.R., $60 \%$ of the respondents agreed that unemployed are likely to participate, $20 \%$ agreed that the self -employed are likely to participate and $20 \%$ agreed that the employed are likely to participate.

Finally from the L.L. project, $57.1 \%$ of the respondents agreed that unemployed are likely to participate, $28.6 \%$ agreed that the self -employed are likely to participate and $14.3 \%$ agreed that the employed are likely to participate. According to the most of the respondents from all the five projects, indicated that unemployed people are likely to participate in EIA. This is because the unemployed are free and have time to attend meetings hence participation would be high. Projects proponents are of the opinion that there's no link between one's employment status and participation. Income is closely 
associated with participation even when taking account of gender, type of family, employment status, ethnic group, educational levels, and region of residence (Ferragina, et. al, 2013).

Poverty is a major hindering factor to individual's participation in County governance. A participant in Masinga mentioned that they even lack money to travel to the venue of the meetings. Moreover, they live from hand to mouth and they were required to work for food on a daily basis (Kalekye, 2016). Results of respondents' are shown below in Table 2.

Table 2: Employment Status

\begin{tabular}{lccccc}
\hline & NaRSIP & NaORIP & NgRD & W.R & L.L \\
\hline Employed & $26.6 \%$ & $33.3 \%$ & $16.7 \%$ & $20 \%$ & $14.3 \%$ \\
Unemployed & $66.7 \%$ & $53.3 \%$ & $50.0 \%$ & $60 \%$ & $57.1 \%$ \\
Self- employed & $6.70 \%$ & $13.3 \%$ & $33.3 \%$ & $20 \%$ & $28.6 \%$ \\
Total & $\mathbf{1 0 0 \%}$ & $\mathbf{1 0 0 \%}$ & $\mathbf{1 0 0 \%}$ & $\mathbf{1 0 0 \%}$ & $\mathbf{1 0 0 \%}$ \\
\hline
\end{tabular}

Source: Author's (2018)

\subsection{Behavioral factors affecting PP in EIA process}

\subsubsection{Ranking of the level of participation in government projects}

From the NaRSIP, $53.3 \%$ of the respondents ranked the level of participation as lowest, $26.7 \%$ of the respondents ranked the level of participation as medium and $20 \%$ of the respondents ranked the level of participation as highest. From the NaORIP $60 \%$ of the respondents ranked the level of participation as medium, $26.7 \%$ of the respondents ranked the level of participation as low and $13.3 \%$ of the respondents ranked the level of participation as highest. From the $\mathrm{NgRDP}, 58.3 \%$ of the respondents ranked the level of participation as lowest, $25 \%$ of the respondents ranked the level of participation as medium and $16.7 \%$ of the respondents ranked the level of participation as highest.

From the W.R., $60 \%$ of the respondents ranked the level of participation as lowest, $30 \%$ of the respondents ranked the level of participation as medium and $10 \%$ of the respondents ranked the level of participation as highest. Finally, from the L.L. project, $71.4 \%$ of the respondents ranked the level of participation as lowest, $14.3 \%$ of the respondents ranked the level of participation as medium and $14.3 \%$ of the respondents ranked the level of participation as highest. Most of the respondents from NaRSIP, NgRD, WR and L.L. ranked participation in government projects as lowest due to lack of agenda as to why the called people to meetings. Most of the respondents in NaORIP ranked participation in government projects as medium.

Studies by the World Bank in Bosnia and Herzegovina established that even though a large number of citizens were not satisfied with their representation in municipal or local authorities' activities, a small minority were willing to participate in such activities. Their participation in local 
government was limited largely because citizens did not believe they could influence local decision-making. As a result, public participation was more reactive than proactive (World Bank, 2009). Results of respondents' are shown below in Table 3 .

Table 3: Ranking of the level of participation in government projects

\begin{tabular}{lccccc}
\hline & NaRSIP & NaORIP & NgRD & W.R & L.L \\
\hline Lowest & $53.3 \%$ & $26.7 \%$ & $58.3 \%$ & $60 \%$ & $71.4 \%$ \\
Medium & $26.7 \%$ & $60.0 \%$ & $25.0 \%$ & $30 \%$ & $14.3 \%$ \\
Highest & $20.0 \%$ & $13.3 \%$ & $16.7 \%$ & $10 \%$ & $14.3 \%$ \\
Total & $\mathbf{1 0 0 \%}$ & $\mathbf{1 0 0 \%}$ & $\mathbf{1 0 0 \%}$ & $\mathbf{1 0 0 \%}$ & $\mathbf{1 0 0 \%}$ \\
\hline \multicolumn{5}{c}{ Source: Author's (2018) }
\end{tabular}

\subsubsection{Whether the respondents will participate in future meetings when called upon}

From the NaRSIP, $47 \%$ of the respondents agreed that they would participate in future projects while 53\% failed to agree. From the NaORIP, $49 \%$ of the respondents agreed that they will participate in future projects while $51 \%$ did not agree. From the NgRDP, 55\% of the respondents were of the opinion that that they will participate in future projects while $45 \%$ were of the contrary opinion. From the W.R., 58\% of the respondents agreed that they would participate in future projects while $42 \%$ failed to agree. Finally, from the L.L. project, $65 \%$ of the respondents agreed that they would participate in future projects $35 \%$ failed to agree.

From the findings, majority of the respondents from the NgRDP, W.R and L.L. projects were positive about participating in future projects when called upon. In a study investigating the influence of community participation in successful implementation of CDF funded projects in Mwea constituency, Kenya, public participation was found to be low (Nyaguthii and Oyugi, 2013). Most of the infrastructure projects in the constituency were mainly identified by either the politicians or the projects committee members. This practice led to misappropriation of public funds and resources. It was noted that only influential people in the community were fully involved in identification, planning and implementation of these projects. Results of respondents' are shown below in Figure 3. 


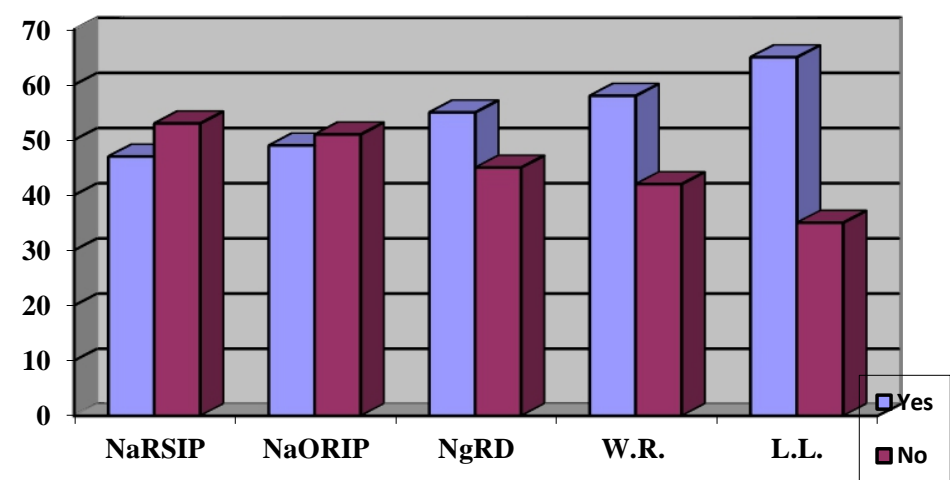

Figure 3: Whether the respondents will participate in future meetings when called upon Source: Author's (2018)

\subsection{Political factors affecting PP in EIA process}

\subsubsection{Conflicts between government and the local people during consultation}

From the NaRSIP, $70 \%$ of the respondents agreed that there were conflicts between government and the local people while $30 \%$ failed to agree. From the NaORIP, $60 \%$ of the respondents agreed that there were conflicts between government and the local people while $40 \%$ did not agree. From the $\mathrm{NgRDP}, 72 \%$ of the respondents were of the opinion that there were conflicts between government and the local people while $28 \%$ were of the contrary opinion. From the W.R., 75\% of the respondents agreed that there were conflicts between government and the local people while $25 \%$ failed to agree. Finally, from the L.L. project, $78 \%$ of the respondents agreed that there were conflicts between government and the local people while $22 \%$ failed to agree.

According to the findings, most of the respondents from all the five projects agreed that there were conflicts between the government and the public. Some of the issues and concerns which lead to disagreement included; the plight of open air traders who had to move to pave way for the road construction, noise pollution by the huge tractors, increase in dust and air pollution, possible loss of land during construction and compensation of the public. Conflicts among the participants may arise from differences in opinions or beliefs, it may reflect differences in interests, desires or values, or it may occur as a result of scarcity of some resources. Conflict can occur in a competitive context (Scott and Ngoran, 2003). Results of respondents' are shown below in Figure 4. 


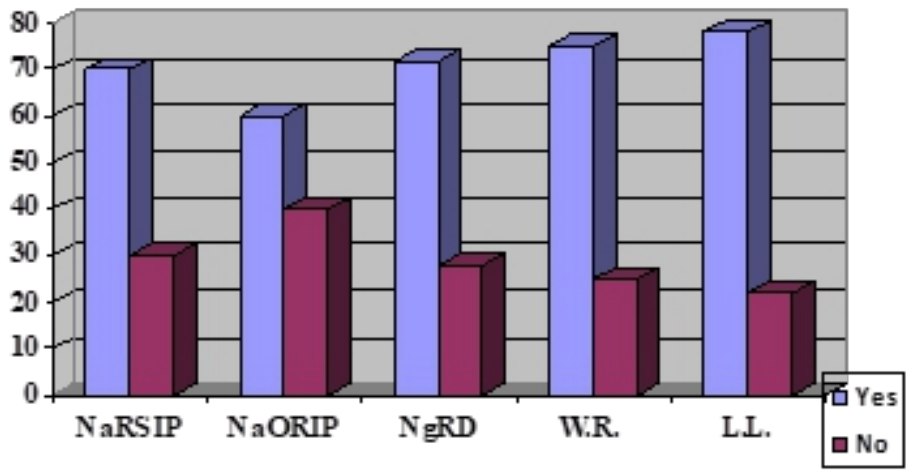

Figure 4: Conflicts between government and the local people during consultation Source: Author's (2018)

\subsubsection{Conflicts resolution}

From the NaRSIP, $65 \%$ of the respondents agreed that conflicts were resolved while $35 \%$ failed to agree. From the NaORIP, $37 \%$ of the respondents agreed that conflicts were resolved while $63 \%$ did not agree. From the $\mathrm{NgRDP}, 56 \%$ of the respondents were of the opinion that conflicts were resolved while $44 \%$ were of the contrary opinion. From the W.R., $70 \%$ of the respondents agreed that conflicts were resolved while $30 \%$ failed to agree. Finally, from the L.L. project, $72 \%$ of the respondents agreed that conflicts were resolved while $28 \%$ failed to agree. Majority of the respondents from the NaRSIP, NgRDP, WR and L.L. agreed that conflicts were resolved. Majority of the respondents from the NaORIP were of the opinion that conflicts were not resolved.

According to the views of project proponents, issues which were within their control that is, those that they could manage were resolved. The issues that were beyond their scope could not be resolved. Because of the diversity of interests, citizens and project proponents will inevitably encounter conflict. Within all conflict management methods, it is vital for practitioners to identify and understand participant values, distribute power evenly, acknowledge interests, and find common values to successfully resolve conflict (Leung et. al 2013). Results of respondents' are shown below in Figure 5 . 


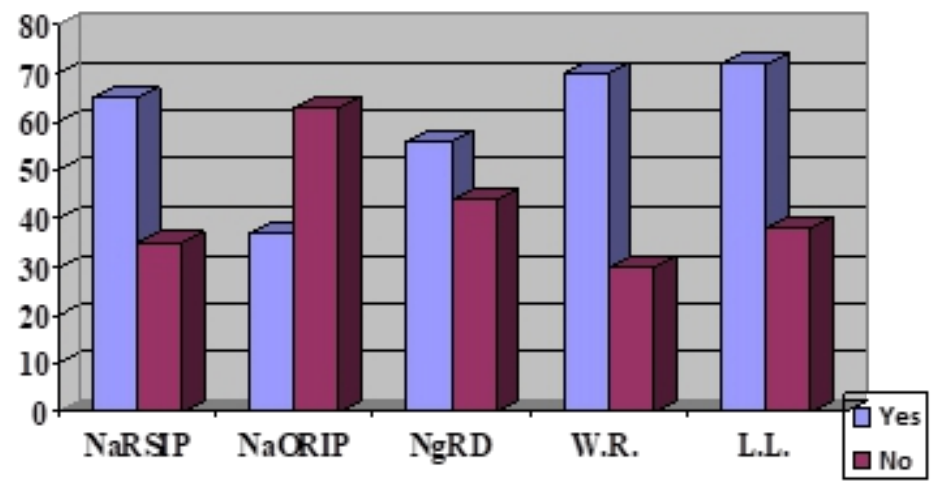

Figure 5: Conflicts resolution

Source: Author's (2018)

\section{Conclusion}

Drawing lessons from the five selected projects, participation in these projects was average. Although there has been tremendous improvement when it comes to public participation in government projects, awareness level among the public about EIA process is still low. Illiteracy affected one's ability in access information about the project. According to projects proponent, some of the public lacked time to find out what the project was all about. Language used in meetings could either encourage/ discourage effective communication between the project proponent and the public and presence of translators in meetings is of importance. There is no relationship on how a person's income level affects their participation however a person's employment status tends to affect how public participate in EIA process. Attitude of the members of the public in current project shape how they are likely to participate in future projects when called upon. Transparency creates trust and lack of transparency of information hinders the public from participating. Conflicts are a common feature in government projects and it is good for all affected parties to resolve them before they escalate.

\section{Recommendations}

\section{The study recommends that:}

- Regularly awareness and sensitization drive by NEMA about EIA process, importance of public participation in EIA process.

- The public ought to be allowed to participate in meetings without discrimination based on political alignments and their income levels. This will encourage effective public participation in government projects.

- Members of the public should change their attitude towards participation in government projects and create time within their busy 
schedules. Their participation will allow their views to be considered in the final decision making process.

- Project proponents ought to employ the services of translators especially in meetings. This will help to ensure that technical language is translated to a simplified language that is understood by everyone.

- Government should carry its affairs in an open and transparent manner. They ought to have a clear agenda and plan as to why people are called to participate in meetings especially in government projects.

\section{Areas of Further Study}

This research study was limited to projects initiated by the government in Nairobi County .This study therefore suggests further studies to be conducted on analysis of public participation in the Environmental Impact Assessment process specifically on donor-funded projects. The study further suggests further studies on the Public Participation provisions in Environmental Impact Assessment.

\section{References:}

1. Ali H. (2018). Determinants of Community Participation in the Implementation of Development Projects: A Case of Garrisa Sewerage Project, Kenya. International Journal of Economics, Commerce and Management, 6(4), 843-855

2. Aregbeshola, M. T. (2009). Public Participation in Environmental Impact Assessment: An effective tool for sustainable development, South African perspective (Gautrain). Unpublished Manuscript, Department of Environmental Sciences, University of South Africa, 5354

3. Daniel Mirisho Pallangyo (2005). Environmental Impact Assessment for mining activities in Tanzania: Legal Analysis. Unpublished Manuscript, Department of Law, University of KwaZulu-Natal, Pietermartzburg, 51-53

4. GoK (2003). Environmental Impact Assessment and Audit Regulations, Legal Notice No 101. Government Printer, Nairobi Kenya

5. Gok (2002). Environmental Impact Assessment Guidelines and Administrative Procedures, Legal Government Printer, Nairobi Kenya

6. EMCA (1999). The Environmental Management and Coordination Act. Kenya Gazette Supplement, Act No.8 of 1999 Nairobi, Kenya

7. Ferragina, E., Tomlinson, M., \& Walk, R. (2013). Poverty, Participation and Choice. York: Joseph Rowntree Foundation Journal of Public Participation 3(1), 12 - 15

8. Gitegi C. and Iravo M. (2016) Factors Affecting Public Participation in Effective Devolved Governance in Kenya: Case Study of Uasin 
Gishu County. Strategic Journal of Business \& Change Management, $3(4), 19-23$

9. B. M. Kosamu, A. A. Mkandawire, W. Utembe and H.W. T. Mapoma (2013). Public participation in Malawi's environmental impact assessment (EIA) process. African Journal of Environmental Science and Technology, 7(10), 307-311

10. John Scott and Jude M. Ngoran (2003). Public participation and environmental impact assessment with case studies from: England, Denmark and New Zealand. Unpublished Manuscript, Department of Environmental, Technology and Social Sciences, Roskilde University, 29-30

11. Kalekye, A. (2016). Determinants of Citizen Participation in Devolved Governance in Kenya: A Case Study of Machakos County. Unpublished Manuscript, Department of Sociology and Social Work, University of Nairobi, 45-47

12. Leung, M.Y., Yu, J., and Liang, Q. (2013). Improving Public Engagement in Construction Development Projects from a Stakeholder's Perspective. Journal of Construction Engineering and Management. 139(11)

13. Mugenda, O. M., \& Mugenda, A. G. (2003). Research methods: Quantitative and qualitative approaches, (Revised Edition- Pp 93-98). Nairobi, Kenya: African Centre for Technology Studies.

14. Munyinda N. S. and Habasonda L.M. (2013) Public Participation in Zambia: The Case Study of Natural Resource Management. Report by Danish Institute for Human Rights (DIHR), 59-60

15. NEMA (2014). http://www.conservationalliance.or.ke Guidelines for EIA Review.

16. Nyaguthii E. and Oyugi L.A. (2013). Influence of Community Participation in Successful Implementation of CDF Funded Projects in Mwea Constituency, Kenya. International Journal of Education and Research, 1(8),

17. Ngonge, D.N. (2015). Evaluation of Public Participation in Environmental Impact Assessment of the Southern By- Pass Road in Nairobi, Kenya. Unpublished Manuscript, Center for Advanced Studies in Environmental Law and Policy, University of Nairobi, 9-10

18. Oyugi, L., \& Kibua, T. (2008). Planning and Budgeting at the Grassroots Level: The case of Local Authority Service Delivery Action Plans. Decentralization and Devolution in Kenya: New Approaches. (T. Kibua, \& G. Mwabu, Eds.) Nairobi: University of Nairobi Press, 2008 
19. Rodenhoff, Vera (2003). The Aarhus convention and its implications for the 'Institutions' of the European Community. Review of European Community and International Environmental Law. 11(3): 343-357.

20. Pius Kahangirwe (2011). Evaluation of Environmental Impact Assessment (EIA) practice in Western Uganda, Impact Assessment and Project Appraisal. Journal of Impact Assessment and Project Appraisal 29(1), 79 - 73

21. U.S. Department Of Transportation (2010). Transportation Capacity Planning Building, "Public Involvement and the Hiawatha Light Rail Transit Design-Build Project” The Metropolitan Council and Partner Agencies, Washington D.C.

22. UN- HABITAT (2001). Tools to Support Participatory Urban Decision Making Urban Governance toolkit Series. UN- HABITAT Self-Assessment Report, 49-50

23. Vivien Lowndes and Lawrence Pratchett (2006). CLEAR: Understanding Citizen Participation in Local Government.

24. Wathome M. D. (2013): Factors Influencing Sustainability of Community Service Order Projects in Kiambu County, Kenya. Unpublished Manuscript, College of Education and External Studies, University of Nairobi, 31-33

25. Webler, T., Tuler, S., Krueger, R. (2001). What is a good public participation process? Five perspectives from the public. Journal of Environmental Management 27 (3), 435-450.

26. World Bank (2009). Environmental Assessment Sourcebook Volume I: Policies, Procedures and Cross-sectoral Issues, World Bank Technical Paper No. 139, Environment Department Washington, DC

27. XiaoHu Wang (2007). When Public Participation in Administration Leads to Trust: An Empirical Assessment of Managers' Perceptions. Journal of Public Administration, 67(10), 265-278

28. Yacoob Abiodun (2016). Elevating public participation in planning practice http://www.environewsnigeria.com/elevating-publicparticipation-in-planning-practice/

29. Zhiqing Zhou (2012). Public Participation in EIA, China. Unpublished Manuscript, School of Environmental Sciences, University of East Anglia, 48-58 